\title{
Barriers to Development and Progress of Women Entrepreneurs in Pakistan
}

\author{
Muhammad Azam Roomi \\ Senior Lecturer/Director of Research \\ Centre for Women's Enterprise \\ University of Bedfordshire Business School \\ Luton, UK LU1 3JU \\ muhammad.roomi@beds.ac.uk
}

Guy Parrott

Senior Lecturer \& Fellow

Bedfordshire Business School

University of Bedfordshire Business School

Luton, UK LU1 3JU

guy.parrott.@beds.ac.uk 


\title{
Barriers to Development and Progression of Women
}

\section{Entrepreneurs in Pakistan}

\begin{abstract}
Encouragement and support of women entrepreneurs can empower them helping them to make an effective contribution to the economic development of their country. However, in many societies such as Pakistan, women may not be able to gain access to the same opportunities as men, due to a number of deeply-rooted discriminatory socio-cultural values and traditions. Furthermore, these restrictions are often found in the very structural and institutional support mechanisms that exist to assist such fledgling business-women.

In Pakistan, women entrepreneurs' full economic potential is not being realized. They can suffer from a lack of access to: capital, land, business premises, information technology, training, and agency assistance. Inherent attitudes of a patriarchal society: that men are superior to women and that women are best suited to be homemakers create formidable challenges coupled with a lack of encouragement from male family members, resulting in limited spatial mobility and a dearth of social capital.

The research suggests that to foster development, multi-agency cooperation is required. The media, educational policy makers and government agencies should join forces to provide improved access to business development services (BDS) and the facilitation of a local, regional and national network for women entrepreneurs, thereby assisting them to become more integrated into the mainstream economy.
\end{abstract}

Keywords: Women's Enterprise Development, Female entrepreneurship, Islamic Society, Pakistan, Gender related challenges. 


\section{INTRODUCTION}

Many of the emerging theories and 'recipes' for success for women entrepreneurs have been derived from the growing body of knowledge garnered from studies conducted in developed countries (Lerner et al., 1997). There is a relative scarcity of published research conducted within developing countries (Allen and Truman, 1993). Studies researching the role of female entrepreneurs in the developing world, relate to the very poor and often uneducated segments of women located in rural or lowerskilled urban sectors. The majority of this work has been commissioned by international development agencies, where the prevailing focus is centered on women's concerns from a 'macro-perspective' viewpoint (Wees and Romijn, 1987). These studies however, critically omit the formation of an in-depth understanding of the nature of women's entrepreneurship within developing economies. This critical omission has led to a situation where studies fail to fully capture the impact and role of social structures, work, family, and organized social lives which can vary widely in developing countries (Allen and Truman, 1993; Aldrich, 1989).

Women's entrepreneurship development theories have emerged primarily from research carried out in developed countries, it is therefore important to examine the extent to which these theories apply to developing countries such as Pakistan, where social and familial control over women; their economic dependence on men, and restrictions on their mobility determine the differential access that males and females experience concerning education and other key supporting services. 
The status of women in Pakistan is not homogenous, primarily because of the interconnection of gender with other forms of exclusion in society. Religious prescriptions, cultural norms and actual practice, related to women's status and role, vary widely and are sometimes highly contradictory. There is also considerable diversity in the status of women across the classes (the socio-economic status of a woman's family), geographical regions, ethnic origin and the rural/urban divide due to uneven socioeconomic development and the impact of tribal, feudal, and capitalist social formations place on women's lives. However, regardless of which class or region they hail from, a women's situation, in comparison to men is one of systemic subordination, determined by the forces of patriarchy. These practices greatly influence the occupational roles available to women across all the regions of Pakistan. The role of women is fundamentally influenced by two significant mores, one being the cultural norm of 'Pardah' (veil). "The literal meaning is curtain, and describes the system of the seclusion of women and the general enforcement of 'high' standards of female modesty in South Asian societies, such as India and Pakistan. Furthermore, there are two sub-divisions within Pardah, the system of female seclusion and sexsegregation, defining different spatial boundaries for the day-to-day activities of men and women. Women's activities are mainly limited to the domestic arena, while men are encouraged to seek employment in industry and commerce. The second is the veil, or the concealing cloak known as the 'burqa', worn by women whenever they venture outside the home. The veil or 'burqa' can be described as a portable means of seclusion (Papanek, 1982).

Another significant cultural norm affecting the development of women entrepreneurs is the notion of 'Izzat' (honor) "Women are considered to be the repositories of a 
family's honor, and their chastity and good reputation is highly valued and guarded" (Shaheed, 1990: 27).

\section{AIMS AND OBJECTIVES}

The principal aim of this study is to present a micro-level perspective on the genderrelated challenges and opportunities of women entrepreneurs in the context of the socio-economic landscape of Pakistan. The study also focuses on the fact that evidence implies that women entrepreneurs experience gender-neutral constraints, such as the lack of access to, including control over, capital, land, business premises, information and technology, training, production inputs, and assistance from governmental agencies; but records citations from women entrepreneurs facing gender-related constraints. The research catalogues the additional challenges women experience related to their gender, emanating from traditions based on: feudal, tribal, and geographical traditions. These practices are often wide ranging and their existence is justified as the maintenance and promotion of religious values.

This study aims to make a contribution to a deeper understanding of women's entrepreneurship in a different and often challenging cultural setting, and to furthermore, assist policy makers and development agencies to understand the specific needs of female entrepreneurs. This study also sets out to consider the constraints that can rein in female entrepreneurship and proposes methods to effectively unlock the entrepreneurship potential of women within an Islamic society. With these aims and objectives in mind, the research was guided by the consideration of three principal questions: 
- Which specific gender-related factors influence the entrepreneurial capabilities of Pakistani women?

- What is the effect of the practice of the cultural norms of 'Pardah' (veil) and 'Izzat' (honor) upon the performance of these female business owners?

- What policies could be pursued to promote the entrepreneurship potential of women in an Islamic society like Pakistan?

\section{METHODOLOGY}

The method used to collecting primary information was a series of in-depth; one to one semi-structured interviews conducted with a sample of 256 women entrepreneurs (individually) in the five major metropolitan cities of Pakistan. These in-depth interviews were considered to be the most appropriate data gathering method for two reasons. Firstly, the indigenous researcher was able to draw on his own understanding of how the respondents view and experience the world in supplementing and interpreting the data. Secondly, the in-depth interview not only enabled the researcher to capture the data in response to structured quantitative sections within the questionnaire, but also assisted in accessing the detail required to gather sufficient qualitative analysis within a relatively short time frame spent meeting the respondents. It was of particular importance to enable the participants to discuss what they believed was important from their perspective, to capture their perceptions and feelings within the time permitted and the practicality of the access granted to the researcher. 
A sample of approximately 100 names of female entrepreneurs was selected in the beginning by using a random sampling framework, utilizing information sourced via the Federation of Pakistan Chambers of Commerce and Industry (FPCCI), Export Promotion Bureau (EPB), Small and Medium Enterprise Development Authority (SMEDA), First Women's Bank Limited (FWBL), WEXNet-2001, and local directories/yellow pages. Many of the initial participants were generous in providing further names of potential participants to be contacted. The sample was stratified according to geographical location covering the five major cities of Pakistan, namely: Karachi, Lahore, Rawalpindi/Islamabad, Quetta and Peshawar. The respondents worked in areas, including manufacturing, retailing and the services sector. At least twenty five women entrepreneurs were selected from each city and specific operational sector.

The interviews were conducted either at the respondents' business premises or at WEXNet (an exhibition organized by the Export Promotion Bureau and the Federation of Pakistan Chambers of Commerce and Industry). The researcher's affiliation with a leading business school and previous experience providing Business Development Services (from prominent platforms such as EPB and FPCCI) to women entrepreneurs over several years, not only helped to increase the response rate, but also assisted in reassuring respondents thereby enabling them to give their views freely and without the unnecessary encumbrances of meeting a completely 'unknown' researcher.

The women entrepreneurs interviewed were either owners of, or held a controlling interest in an enterprise and managed it on a day-to-day basis. From a total of 265 
people contacted, only four declined, three were unavailable and in two cases it was not possible to arrange a meeting. Out of 256 interviews, 239 were held on one-onone basis, where only the researcher and the respondents were present. In the remaining seventeen interviews, nine were conducted in the presence of women entrepreneurs' employees, and eight in the presence of their children or siblings. All the interviewees were assured that all information provided would be treated in the strictest confidence. In addition to this pledge, respondents were informed that all information would be used in combination with other responses and no names would be cited in the study. This measure was utilized to increase the reliability and credibility of the information provided during the interviews.

\section{STRUCTURAL PROFILE}

Analysis of the data gathered through the research showed that a significant number of the women entrepreneurs (34\%) owned or managed micro enterprises. Thirty six percent of the businesses could be categorized as 'small businesses' and $10 \%$ of the entrepreneurs controlled small to medium enterprises. These results are close (within +/- five per cent) to the structural profile of the women entrepreneurs described by a study conducted by ILO in 2001 (Goheer, 2002). The majority of the businesses $(82 \%)$ operated within the traditional sectors of textiles and apparel, education, food, beauty, and the health sector.

Throughout the research deeply rooted socio-cultural values of female segregation were found to be evident. A significant number of the female entrepreneurs (47.7\%) were concentrated in the services sector and operated at the local market level, 
marketing the vast majority of these services to female customers. This is typical of women's' enterprises in other Islamic countries, where the initial investment is relatively small as life experiences, hobbies and interests are further developed into fledgling businesses (Al-Riyami et al, 2003). Most of these services were provided in sectors where male-female interaction is either non-existent or at a minimum level (as witnessed in the education, beauty and the food sectors). Within the manufacturing sector the female entrepreneurs $(34.4 \%)$ were based primarily, in the apparel and textiles sector, where the majority of their employees were female. A smaller number of female entrepreneurs (19.9\%) were engaged in the retail sector. This smaller number was primarily as the result of an increased incidence of male-female interaction. This factor effectively acts as a major constraint upon female entrepreneurs wishing to operate in the retail sector. This constraint is particularly pernicious within this sector as it traditionally offers many business people entrepreneurial opportunities across the globe. This barrier acts as a major deterrent to female entrepreneurs who have little or limited resources to challenge the status quo in this significant and sizeable business sector.

\section{PERSONAL PROFILES}

The prevailing literacy rate has a profound affect in informing Pakistani women of their rights (Shah, 1985). The study confirmed that those women receiving an advanced level of education were more likely to become an entrepreneur, indeed the fact that $82 \%$ of the sample benefited from being at least high school graduates supports this proposition, $52.7 \%$ of the respondents held a bachelor degree and a smaller percentage of $15.2 \%$ of the respondents held a post-graduate qualification. 
Another significant finding is that their close relatives including father, mother, and spouse also possessed above average levels of literacy and numeric skills. However, only 15.2 percent of the respondents had benefited from a formal management education program, 21.8 percent of the respondents had previous managerial experience and 25.7 percent of the respondents had some previous experience in industry.

TABLE 1

Personal Profile for Pakistani Women Entrepreneurs

\begin{tabular}{|l|l|l|l|}
\hline Variable & Number & Percentage & Mean \\
\hline Education level/high school & 212 & 82.8 & \\
\hline Education level/university (Bachelor) & 135 & 52.7 & \\
\hline Education level/university (Master) & 39 & 15.2 & \\
\hline Area of university education: & 39 & 15.2 & \\
\hline management, economics, etc. & & & \\
\hline Previous entrepreneurial experience & 23 & 8.9 & \\
\hline Previous managerial occupation & 56 & 21.8 & \\
\hline Previous experience in industry & 66 & 25.7 & \\
\hline Involvement in the start-up & 244 & 95.3 & \\
\hline Membership in women's association & 77 & 30 & 39 \\
\hline Age of entrepreneur & & & \\
\hline Marital status: currently married & & 77 & \\
\hline Number of children & & & \\
\hline First child's age & & & \\
\hline Father and/or husband in business & 179 & 69.9 & \\
\hline
\end{tabular}


Another significant finding is that almost $70 \%$ of the respondents had close male relatives working in business at the time of their start-up. These relatives also greatly supported their daughters and wives in the start-up phase, or at least encouraged them to 'take the plunge'. Most of the respondents $(77 \%)$ were married with children and only became entrepreneurs when their children were older. This finding is consistent with the strong family orientation prevalent in Pakistani culture and the tolerance of working women, as long as they continued to give priority to their family responsibilities. A relatively small percentage (15.2\%) of the respondents had studied 'business' related subjects at university level. This fact can be explained to some extent by the social mores that women advised by important family members, even at the university education level, traditionally opted to study non-commercial femalespecific subjects. Only 13 percent of the interviewees were members of a women's association thereby receiving support and succor from a group of their peers. The majority $(87 \%)$ did not benefit from access to a peer support group. This can to an extent, be explained by the general lack of mobility most female entrepreneurs continue to endure.

All interviewees were categorized into three distinctive and specific groups, namely as personal freedom seekers, personal security seekers or personal satisfaction seekers. The underlying influences shaping their enterprises included: family encouragement, ambition, independence, enjoyment, finance, economic necessity, challenge, corporate downsizing, job dissatisfaction, utilization of knowledge or skills, to make others happy, and the need to gain self recognition. (Al-Riyami, 2002; Shabbir, 1996). Almost half of all the women interviewed (48\%) founded their business with the principal aim to maintain or improve both their personal and their 
family's social and economic status. The need for increased personal security and maintaining social and economic status was in many cases triggered by an unforeseen event; including the death or retirement of the primary 'breadwinner' in the family. This factor represents a major challenge to all stakeholders concerned with developing female entrepreneurship opportunities. High unemployment rates, fierce competition for a limited number of jobs, meager salaries, long working hours and poor working conditions (Goheer, 2002) are some of the "push factors" encouraging women to become self-employed. They make this decision based on need rather than becoming an entrepreneur through an inherent desire to create their own businesses, to develop their economic prosperity, and to become less reliant on the income of male-family members.

TABLE 2

Category of Entrepreneurs based on Reasons for Starting up a Business

\begin{tabular}{|l|l|l|}
\hline Category & Number & Percentage \\
\hline Personal freedom seekers & 52 & 20.3 \\
\hline Personal security seekers & 123 & 48.0 \\
\hline Personal satisfaction seekers & 81 & 31.7 \\
\hline
\end{tabular}

$(n=256)$

A significant number of women in this study $(31.7 \%)$ were no longer content with their role as a homemaker. They took a decision to manage their own enterprise in order to prove to themselves and to others that they were a useful and productive member of society. Most of the respondents within this category were relatively older women in their forties and early fifties, and had little or no previous formal work experience. 
Only $20 \%$ of the sample made a conscious decision to enter business in order to benefit from the freedom to choose their own kind of work, hours, environment, and colleagues. The women in this category had previously experienced some kind of frustration in paid work and now desired the opportunity to gain greater control over their working environment and type of employment (Shabbir, 1996).

A number of entrepreneurs (48\%) took the decision to run their own businesses as a result of their perceived need to seek a greater level of personal security. They were however, often forced into making this decision through a significant change in their personal circumstances, such as the death of their husband, who had previously provided the household's main income. A notable trend emerged, that despite possessing the necessary background and prerequisites to become an entrepreneur many respondents only became an entrepreneur through their proximity to an unplanned or unforeseen event such. A smaller, but notable proportion of the respondents became an entrepreneur as a result of the frustration they experienced following an unsatisfactory period spent working as an employee.

Based on the findings of this study and with reference to the literature (Goheer, 2002; Rajivan, 1997; Shabbir 1995; Shah, 1986), one can begin to construct a profile of a typical Pakistani woman entrepreneur. A set of common characteristics can be observed which include; a woman in her thirties or early forties; holding a university/high school education, (though often unrelated to business) concentrating on a single enterprise, unwilling to diversify into multiple business areas. The respondents shared a similar trait in that they were initially reluctant to enter into business. Many respondents reported that they struggled to deal with their multiple 
roles, running their enterprise and managing homes as well as raising their children. They do however, often benefit from at best, a supportive family, or at worst, a nonobjecting group of male and female relatives. Women entrepreneurs, have to develop coping strategies within a largely unsupportive society which often views women's enterprise as secondary in importance and magnitude to managing and nurturing their families.

\section{CHALLENGES}

An important question in entrepreneurship studies is whether women entrepreneurs face specific problems in setting up a business that are significantly different from those faced by male entrepreneurs. Many researchers (Welter, 2004; McManus, 2001; Smallbone et al., 2000) indicate that women entrepreneurs experience a number of problems and issues that are greater than those faced by small business people in general. In order to promote consistency as with previous research studies (Welter, 2004; Smallbone et al., 2000; Carter et al., 1998), challenges/issues were divided into gender-neutral and gender-related categories.

Gender - Neutral challenges faced by small business owners irrespective of their gender (however, in a patriarchic society the intensity of these challenges intensifies as a result of the socio-cultural restrictions placed upon women) are listed in Tables 3 and 4. The interviewees were also asked to describe the three biggest challenges faced in descending order in both the start-up and growth phases (the findings are presented in tables $3 \& 4$ ) of their business enterprise. 
The greatest gender-neutral challenge cited was access to capital, followed by lack of business management skills, and restrictive government regulations whilst operating in the start-up phase. Again, access to finance was considered to be the most difficult challenge, followed by the availability of the market and lack of technical skills in the development (growth) phase. These results confirm the findings of previous studies (Nabeel, 2002; Roomi, 1999). In addition to gender neutral problems, female entrepreneurs have to overcome structural immobility issues imposed upon them through the preponderance of the practices of 'Pardah' and 'Izzat'. Their lack of access to capital can be considered to be a significant problem as this can constrain the female entrepreneur as she begins to mobilize by raising the requisite start-up working capital, credit guarantees and investment capital. Although not necessarily the norm, there is evidence to suggest a discriminating attitude is displayed by some bankers (Carter and Rosa, 1998).

The combination of both gender neutral and gender related constraints presents the potential and practicing female entrepreneur with several major challenges and issues that they need to overcome to successfully navigate through the period while they are establishing their enterprise. These challenges and issues can seem to be daunting. Often to such an extent that only an extremely determined and motivated individual will be able to withstand the considerable pressures and clear the barriers facing them as they establish their business enterprise. If such an individual does not enjoy the support of their family then it would appear that it would be nigh impossible for them to succeed in the longer term. There is therefore, a compelling case for the establishment of a support network to assist these fledgling entrepreneurs; especially whilst in the start up and early growth stages of their enterprise development. 
TABLE 3

Gender-Neutral Challenges* Faced in the Start-up Phase

\begin{tabular}{|l|l|l|l|}
\hline Problems/Challenges & $\begin{array}{l}\text { 1st challenge } \\
(\% \text { age })\end{array}$ & $\begin{array}{l}\mathbf{2}^{\text {nd }} \text { challenge } \\
(\% \text { age })\end{array}$ & $\begin{array}{l}3^{\text {rd }} \text { challenge } \\
(\% \text { age })\end{array}$ \\
\hline Access to Finance & 39 & 27 & 21 \\
\hline Lack of business management skills & 18 & 21 & 25 \\
\hline Government policies/regulations & 8 & 16 & 14 \\
\hline
\end{tabular}

*Three most difficult challenges during the process in descending order

Many female entrepreneurs are reluctant to approach banks because of the limited availability of collateral, making it difficult for them to formulate and develop a viable business plan. They often face a challenging set of social mores while interacting with male bank professionals. They therefore, have to raise the majority of operational finances through their personal savings, family resources and other financial support from friends. Because of the risk of limited earnings in the start-up phase, many women entrepreneurs find it difficult to access significant start up capital. It is often only possible for a female entrepreneur to start a business if her family has some start-up capital readily available. This problem represents a significant challenge to Government and other support agencies to provide the essential seed funding that will encourage more female entrepreneurs to enter the market place. A structured provision of improved access to business start up capital would help in some way to alleviate the problem. 
TABLE 4

Gender-Neutral Challenges * Faced in the Development (Growth) Phase

\begin{tabular}{|l|l|l|l|}
\hline Problems/Challenges & $\begin{array}{l}\text { 1st challenge } \\
(\% \text { age })\end{array}$ & $\begin{array}{l}2^{\text {nd }} \text { challenge } \\
(\% \text { age })\end{array}$ & $\begin{array}{l}3^{\text {rd }} \text { challenge } \\
(\% \text { age })\end{array}$ \\
\hline Access to Finance & 27 & 23 & 18 \\
\hline Availability of Market & 18 & 21 & 26 \\
\hline Lack of Technical skills & 16 & 24 & 21 \\
\hline
\end{tabular}

*Three most difficult challenges during the process in descending order

The restricted interaction of female entrepreneurs with male members of society limits the opportunities to acquire business management and technical skills, as there are very few institutions/organizations providing specific training for women. They also face severe competition when embarking on gaining access to the marketplace. Men are more able than female entrepreneurs to move freely in society and interact with their peers. Within the wider areas of society such as the administration of Government agencies, men relate to women differently than they do to their male colleagues (Al-Riyami, 2002). Women are often encouraged to stay longer when they are attending official meetings, resulting in unnecessary delays receiving responses to their queries.

As a consequence it can take longer for women entrepreneurs to complete a comparable task than their male counterparts. This can often cause frustration for those women and thereby acts as a discouragement to some potential women entrepreneurs during the crucial start up phase of their business development. 


\section{GENDER-RELATED CHALLENGES}

The interviewees were asked to describe the gender-related challenges they face in the start-up and growth phases of their enterprises. Not surprisingly, spatial mobility was considered to be the most challenging factor in starting up a business. This restriction consists of two dimensions; one being the physical and structural limitation on the ability of women to move around because of the inadequacy of public and private transportation facilities (Shabbir, 1996). The second dimension focuses on the inability of women to move around freely in a social context. From early childhood, women are often not permitted to leave their houses and to independently mix with boys. They are protected and not encouraged to do things independently, notwithstanding the fact that attitudes have changed over time. Women are now increasingly allowed to work in offices from nine to five, but it still remains very difficult for female entrepreneurs to move around as freely as their male relations while conducting their business.

the process in descending order

As a consequence of mobility restrictions women entrepreneurs are forced to operate in specific businesses sectors including, education, health and beauty, where they can provide the vast majority of their services to female customers. They also operate within the garment/textile sector, where traditionally women entrepreneurs manufacture products for female customers. Though, one can find a few women working in non-traditional areas, they are still in the minority as the most important 
reason for their presence in these sectors is the tacit involvement of their male family relatives, enabling them to manage these 'non-traditional' sector-based enterprises.

As their businesses grow, many women entrepreneurs agree that their most daunting challenge is dealing with a male dominated labor force. This is particularly onerous when the labor force consists of largely 'uneducated' males. Some of whom, can be rude, unsupportive and unwilling to accept the authority of a woman. The new breed of female entrepreneurs is therefore required to be forthright in managing this type of labor to achieve their business objectives. Many males still possess a schema of sociocultural values preventing them from readily accepting instructions from a female manager.

Another major gender-related challenge for women entrepreneurs is that of proving their credibility to both their suppliers and customers. The respondents agreed that the acceptance of their authority was a major problem they needed to overcome. This problem is further exacerbated if the female entrepreneur works in a non-traditional sector. They often have to deal with a situation where neither suppliers nor customers take them seriously and instinctively believe that these women entrepreneurs will not be able to achieve their targets. Even more seriously, some suppliers and customers believe that female entrepreneurs will not be able to pay them on time or meet the required production lead times. Therefore, female entrepreneurs have to work much harder than their male counterparts to convince customers, suppliers and even their employees that they are capable of running an effective and efficient business enterprise (Shabbir, 1995). 
All entrepreneurs regardless of gender require information, capital, skills, and labor to successfully establish and develop their businesses. While they hold some of these resources themselves, entrepreneurs often need to seek additional resources by accessing their contacts (Aldrich et al., 1989; Hansen, 1995). These contacts can provide successful routes by which entrepreneurs can gain access to social capital, and thus represents a key component of beneficial networks (Burt, 1992). With respect to social capital and networks, some research indicates gender-specific deficits in the contacts of female entrepreneurs, even in the western sector of the world, drawing attention to the limited outreach and diversity of women entrepreneurs' networks (Cooper, Folta, \& Woo, 1995; Aldrich et al., 1989). This is evident in Pakistan where women entrepreneurs find it difficult to commute, meet their colleagues and get together at a convenient place outside their homes. Many of the women entrepreneurs feel there is a lack of networks enabling them to exchange important information, to discuss pertinent issues, and seek advice on common topics. The respondents felt these would provide them with an effective support framework which ultimately could be vitally important to the successful establishment of their enterprise.

\section{POLICY RECOMMENDATIONS}

The research suggests that many of the problems/challenges faced by Pakistani women entrepreneurs originate from the structurally enforced inferior status of women within an Islamic society, their underestimation as economic agents as well as the gender bias embedded in the regional, tribal, and/or feudal culture present within an Islamic society. Female entrepreneurs have to overcome the significant challenges 
they face in respect to the mores of 'Pardah' and 'Izzat', both of which place severe restrictions on their mobility and their interaction with men at work, as traditionally doubts could be cast on their good reputations and even reduce their marriage prospects in some quarters of society (Shabbir, 1996; Shah, 1986; Hibri, 1982).

The key point worthy of consideration is that there is nothing in the Qur'an (The Holy Book for Muslims) or in the hadith (sayings of The Prophet Muhammad) which prevent women from working outside the home. In fact the Qur'an extols the leadership of Bilqis, (the Queen of Sheba), for her capacity to fulfill the requirements of the office, for her political skills, the purity of her faith and her independent judgment (Al Naml, 27:23-44). If a woman is qualified and the one best suited to fulfill a task, there is no Qur'anic injunction that prohibits her from any undertaking because of her gender. The hadith literature is replete with women leaders, jurists and scholars, and women who participated fully in public life. There is another hadith which states that ninety per cent of our sustenance comes from business. For those who are able and are competent, Islamic society should encourage them to become entrepreneurs or to become actively involved with other types of business activities (Hibri, 1982).

It is a fallacy to say women do not need work and that men have the primary responsibility to provide for their families. The glowing role model of Prophet Muhammad's wife Khadija, RA (the first wife of the Prophet Muhammad, was one of the most successful traders of Makkah) and many other examples in the annals of Islamic history confirm that "women in business" are not frowned upon in Islam (Haddad, 1998). Though Khadija was unable to travel with her trade caravans (because of the social and cultural traditions of Arabian Peninsula at that time) and 
had to rely on someone else, to whom she paid a commission, to act as her agent to trade on her behalf. However, she continued trading this way and confirmed by her action that women are allowed to generate moneymaking activities thus helping improve the economic state of the family, and the community. Therefore, Pakistani society's inclination to effectively deny women the right to work on the basis of religion is an unrealistic and largely historic proposition. In areas of society women have been denied the right to access an education even though Islam has make it compulsory for men and women to pursue knowledge. Islam has given women the right to own property, to own businesses, to keep their 'maiden name', to choose her spouse, to divorce, to hold political office, and to enjoy equality in honor and respect (Ahmad, 1992). The right to work is also an inalienable right of women, which has never been prevented by Islam. If this right is denied, it will, as a consequence, deprive women the ability to make a choice in many areas and affect other inter related rights such as mobility, decision making, and entering into politics (Jalal, 1991). Therefore, the prevailing situation demands that the following steps need to be taken to improve women's entrepreneurship opportunities:

- The first and foremost priority should be the 'true interpretation' of the status of women in an Islamic society. There is a need to change the current thinking at school level to promote the inclusion of women in economic activities. This would help by changing the stereotypical images of women in society and encourage family support and help. Thereby encouraging young women to develop entrepreneurial ambitions.

- Inadequate public transport plays a major role in restricting the mobility of women in Pakistan. Transport facilities such as buses and vans continue to segregate genders by providing separate seating for men and women. While 
traveling on public transport women are confined to the first two or three rows of seats. Men can access any or all the remaining seating. These seating arrangements may have been adequate forty years ago, when few women needed to travel to work, but society has changed markedly since these times. A greater and increasing number of women are now traveling to work, and their demand for facilities has increased manifold, however, only two or three rows still remain available for women traveling on public transport (Shabbir, 1995). There is a pressing need to change this system or at least the provision of seats made available for women traveling in public. Government should take the lead in revising the provision of these services, thereby enabling more women to access transport allowing them to travel more freely in the course of running their enterprises.

- The media could play a pivotal role by portraying the appropriate images of a modern 'Muslim woman' (who has the right to acquire knowledge through education, right to own property and the right to manage their own enterprises). This could be facilitated by publishing images of inspirational and positive role models of successful women entrepreneurs. This would not only provide a source of inspiration for women to make specific career choices, but will also create an environment for family members to provide encouragement as female entrepreneurs seek to establish enterprises.

- Women generally have less access to external funding than men; hence women's businesses tend to be concentrated in the service sectors, which usually require a smaller initial capital outlay as well as less technical knowledge. Government has taken a few steps in improving access to finance such as incorporating the First Women's Bank (a commercial bank for women 
operated by women), and establishing the Pakistan Poverty Alleviation Fund (for the provision of micro-credits to women). However, there is a need for more flexible banking policies especially for women, to encourage the supply of collateral and to support their development of truly viable business plans.

- Research suggests women-only training can play an important role in developing the next generation of business leaders, and enhance their careers (Vinnicombe and Singh, 2003). Limited or non-availability of women-only training opportunities was often cited by the interviewees to be a major constraint to their development of the requisite business management skills, particularly in the crucial start-up and growth phases of their business enterprise. Women-only entrepreneurship training initiatives in addition to, (and not as a substitute for) other entrepreneurship courses together with mentoring and coaching can make a significant difference. Through these measures female entrepreneurs can take the opportunity to learn primary, hands-on techniques of running a business in a socially acceptable and culturally viable environment. These support structures will increase female entrepreneurs confidence enabling them to establish and manage their own businesses in a more effective and efficient manner. Literature confirms that women are more likely to gain intrinsic benefits such as increased confidence, enhanced credibility and more effective inter-personal skills when they undertake women-only capacity building activities (Vinnicombe and Singh, 2003; Simpson, 2000). Once they are able to gain basic knowledge and raise their credibility (in the view of themselves and others) then they can perform more effectively in mixed training activities.

- In parochial commercial environments, there may be limited support to forecast market and financial trends, principally because of lack of data. 
Business support institutions such as the Export Promotion Bureau, First Women's Bank, and the Small and Medium Enterprise Development Authority should develop mechanisms to support women entrepreneurs and assist them in gaining access to international markets. This could be achieved by making the entrepreneurs aware of international demand cycles, underlying trends, and opportunities through capacity building / training, participation in trade delegations and exhibitions, thus establishing sector based training institutions with special emphasis on competitiveness.

- Marketing gaps could be filled through the facilitation of efficient networking amongst women entrepreneurs. Thereby enabling businesses to both develop and progress smoothly. Successful women entrepreneurs could assist in supporting the establishment of mentoring networks facilitating the development of fledgling female entrepreneurs. Regrettably, the existing formal networking organizations such as, chambers of commerce and women's entrepreneurs associations have limited membership and are constrained by their ability to provide a truly regional outreach program. There is an urgent need to assist these existing forums to play a more active and important role by providing the business development services (BDS), required by fledgling female entrepreneurs at this most vulnerable stage of business development.

In conclusion, female entrepreneurs in Pakistan face significant barriers in embarking upon founding a self-owned and self-managed enterprise. The respondents concurred in highlighting significant issues which seriously limit women entrepreneurs' access to necessary funds, knowledge and support frameworks. 
Institutions including Government, although not barring female entrepreneurs, make it harder for them to operate as efficiently and effectively as their male counterparts. Social norms and mores including Pardah and Izzat also significantly restrict the mobility of female entrepreneurs. These mores also create a situation where some men belittle female entrepreneurs with male employees struggling to come to terms with a female manager.

Women entrepreneurs face the same set of challenges their male counterparts face. Female entrepreneurs however, need to deal with additional genderrelated issues. Women entrepreneurs face an additional set of barriers which left unchallenged could prevent many potential female entrepreneurs from entering the marketplace.

The economy could pay a high price if training needs remain unfulfilled and gaps in the market remain unplugged. Perhaps more importantly a valuable resource - female entrepreneurship will be left untapped and additional levels of innovation and wealth creation will not be realized. 


\section{REFERENCES}

Ahmed, L. (1992), Women and gender in Islam: historical roots of a modern game. Yale: Yale University Press.

Aldrich, H. (1989), Networking among women entrepreneurs in O. Hagan, C. Rivchun, and D. Sexton, eds., "Women-Owned Businesses". New York: Praeger, pp. 103-132.

Allen, S., and Truman, C., eds. (1993), Women in Business: Perspectives on Women Entrepreneurs, London: Routledge Press.

Al-Riyami, R., Warren, L., and McElwee, G. (2003), Women Entrepreneurs in Oman: Some barriers to success, Career Development International, 8 (7), p339-346.

Birley, S. (1989), Female entrepreneurs: are they really any different? Journal of Small Business Management, pp. 32-7.

Burt, R.S. (1992), Structural Holes: The Social Structure of Competition. Cambridge, MA: Harvard University Press.

Carter, S. and Rosa, P. (1998), The financing of male- and female-owned businesses, Entrepreneurship and Regional Development, Vol. 10 No. 3, pp. 203-24.

Cooper, A.C., Folta, T.B., \& Woo, C. (1995), Entrepreneurial information search, Journal of Business Venturing, 10(2), 107-120.

Goheer, N. (2002), Women Entrepreneurs in Pakistan: A Study to understand and improve their bargaining power, ILO, Geneva.

Haddad, Y. and Esposito, J. Eds. (1998), Islam, gender and social change, NYC:

Oxford University Press.

Hibri, A. ed. (1982), Women and Islam. Great Britain: Paragon Press. 
Jalal, A. (1991), The convenience of subservience: women and state in Pakistan in Kandiyoti, D. ed. Women, Islam and the state. Philadelphia: Temple University Press. Hussain, A. (1994), Poverty Alleviation in Pakistan, Vanguard Books Lahore, Pakistan. Lerner, M., Brush, C., Hisrich, R. (1997), Israeli women entrepreneurs: An examination of factors affecting performance, Journal of Business Venturing 12, 315339.

OECD Newsletter, (1993), The Rise of Women Entrepreneurs.

Papanek. H. (1982), Pardah in Pakistan: seclusion and modern occupations for women in H. Papanek and G. Minault, ed. Separate Worlds, Chanakya publications, New Delhi.

Shah. N .M. (1986), Pakistani women. Pakistan Institute of Development Economists, Islamabad.

Simpson, R. (2000), A voyage of discovery or a fast track to success: Men, women and the MBA, Journal of Management Development, 19 (9), 764-82.

Rajivan, K.A. (1997), A business of her own: Fifty women in enterprise in India, Chinnai, East-West Books, India.

Renzulli, L.A., Aldrich, H. and Moody, J. (1999), Family matters: gender, networks, and entrepreneurial outcomes, manuscript prepared for submission to Social Forces, University of North Carolina.

Shabbir, A. (1995), How gender affects business start-up - evidence from Pakistan, Small Enterprise Development Journal 6(1).

Shabbir, A., Di Gregorio, S. (1996), An examination of the relationship between women's personal goals and structural factors, Journal of Business Venturing, 11 (6), p507-530. 
Shah. N .M. (1986), Pakistani Women, Pakistan Institute of Development Economists, Islamabad.

Shaheed. F. (1990), Pakistan's women: an analytical description, SANJH, Lahore.

Smallbone, D. et al. (2000), Young Entrepreneurs, Women Entrepreneurs, Ethnic Minority Entrepreneurs and Co-Entrepreneurs in the European Union and Central and Eastern Europe, Summary Report, CEEDR, Middlesex University Business School.

Vinnicombe, S. and Singh, V. (2003), Women-only management training: An essential part of women's leadership development, Journal of Change Management, 3(4), p 294-306.

Wees. C. van der and Romijn, H. (1987), Entrepreneurship and small enterprise development for women entrepreneurs in developing countries, International Labor Office. Geneva. 